\title{
The Challenges facing Smart Technology Use in the Implementation of Electronic Education and Export Education
}

\author{
Adewunmi Obafemi Ogunbase \\ Department of Information Technologies Studies, \\ Faculty of Engineering, \\ Vidzeme University of Applied Sciences
}

\section{INTRODUCTION}

There are several socio-political challenges facing the choice of multi-media and ICT use for the implementation and acceptance of electronic education and export education (e-education) as new smart technologies are applied to the teaching-learning process of higher education (HE) institutions. As a result of a proliferation of smart technologies use in this domain, there is a need for smart educational institutions to export education through electronic education across their international boundaries and for them to assess the socio-political problems facing this form of digital education.

This study will examine and identify the socio-political challenge facing smart technology use in e-education through electronic education across international boundaries.

This is important as HE institutions have witnessed a growth of technological expansion and uses as helpful means to increase the effectiveness and efficiency of digital education and the changed academic lives and perspectives of digital world.

It will support and suggest improvements to the continuous development of ICT use for e-education that will result in an efficient and cost effective means of teaching-learning in HE institutions.

\section{HYPOTHESES}

- How does the socio-culture attitude and political policies affect the expansion and multi-media technology uses for e-education and electronic education in $\mathrm{HE}$ institutions?

- How do we promote this continuous expansion and multi-media technology use in digital education through a transformation of users' socio-cultural attitude and political policies affecting its effectiveness and efficiency?

H1 - Users' socio-cultural attitude and government-political policies have considerable effects on the expansion and multimedia technologies' uses for e-education through electronic education.

H2 - Users' socio-cultural attitudes can be modified and improved towards more effective and efficient digital education for e-education in HE institutions.

\section{LITERATURE REVIEW}

The essence of this research study is based on the derived assumptions that:

- Multi-media technologies' use in web-based learning environments are carried out within the influence of societal culture and cultural adaptation in creating successful ICT tools for use in digital education.

- Uses of web-based learning environments are carried out within the influence of social culture and learners' learning culture (Senouci et al 2015; Ogunbase, A. 2016; Ogunbase, A. \& Raisamo, R. 2017).

These researches highlighted the techniques that were expected to be relatively easy to use and could be adopted by many students and teachers. These techniques include an elaborative learning culture, learning styles and acceptability designs for digital education.

This new study will focus on previous studies' results/findings and examine/identify expected new results of users' socio-cultural attitude and political policies affecting effective and efficient technology use for e-education.

\section{METHODOLOGY}

Mixed-methods methodology will be used that will involve a questionnaire and interview questions. In analysing the data collected, relevant statistical techniques will be adopted to report results.

\section{RESULTS}

It is expected that this study will get to the extent at which socio-cultural attitude and political policies affect the expansion and multi-media technologies' use for e-education in HE institutions which will help learning management systems, researchers and education actors in using new smart technologies in the teaching-learning process of HE institutions.

\section{KEYWORDS}

Smart technology, electronic education, export education

\section{REFERENCES}

Ogunbase, A. (2016). Pedagogical Design and Pedagogical Usability of Web-Based Learning Environments: Comparative Cultural Implications from Africa and Europe. ISBN 978-951-44-9756-8, ISSN 1795-9489.

Ogunbase, A. \& Raisamo, R. (2017). The Project Case: A West African Digital University. In Stakeholders and Information Technology in Education Book. ISBN 978-3319-54687-2.

Senouci, A. et al (2015). Impediments to the Integration of ICT in Public Schools of Contemporary Societies: A Review of Literature. Journal of Information Process Systems, Vol.14, 252 269, 2018. 